\title{
Counseling, Progressive Relaxation, and Writing a Journal to Reduce General Anxiety Disorder Symptoms in an Undergraduate Student from Universitas Indonesia
}

\author{
Vitriyanti Sukarno Karyo a and Ina Saraswati ${ }^{\mathrm{b} *}$ \\ ${ }^{a}$ Clinical Adult Magister-Profession, Faculty of Psychology, Universitas Indonesia, Depok, \\ Indonesia; ${ }^{b}$ Clinical Psychology Department, Faculty of Psychology, Universitas Indonesia, \\ Depok, Indonesia.
}

*Corresponding Author:

Ina Saraswati

Clinical Psychology Department

Faculty of Psychology, Universitas Indonesia

Jl. Lkr. Kampus Raya, Depok, Jawa Barat

Indonesia, 16424

Tel.: +62 217270004

Email: ina.saraswati@gmail.com 


\section{Counseling, progressive relaxation, and writing a journal to reduce general anxiety disorder symptoms in an undergraduate student from Universitas Indonesia}

This study describes how counseling, progressive relaxation, and writing a journal can assist a student in reducing symptoms of general anxiety disorder (GAD). The participant in this study was a 21-year-old girl who reported being anxious in several areas of her life, namely, academic, friendship, religion, and love. To deal with her GAD symptoms, counseling sessions that consisted of promoting internal lifestyle changes were conducted three times, and each session ended with progressive relaxation. Journal writing was given as a home assignment at the end of the second and third sessions. During the last session, the participant conveyed that her worries had lessened, and she was feeling more comforted and less anxious. She also reported that she had better quality of sleep.

Key words: counseling, progressive relaxation, writing journal, general anxiety disorder

\section{Introduction}

Generalized anxiety disorder (GAD) is a condition deemed as chronic anxiety with indications of excessive and uncontrollable worry accompanied with somatic symptoms. Unlike other anxiety disorders, GAD involves diffuse anxiety lacking specified fear, stimuli, or situation. Individuals who suffer from GAD fear and avoid a mixture of elusive stimuli from within and outside themselves (Stevens, 2008). Such individuals reported being physically tense throughout their lives or excessively worried in their adolescence. Such clinical observations were supported by empirical data provided by Hoehn-Saric, Hazlett, and McLeod (1993 in Stevens, 2008). Bhawanjee and collages (1998 in Stevens, 2008) demonstrated that women are affected by GAD twice as often as men, although not in the case among South Africans. As mentioned in the fourth edition of Diagnostic and Statistical Manual of Mental Disorders -text revised (DSM-IVTR), individuals who are susceptible toward anxiety disorder are shy, lonely, isolated, have low self-esteem, and feel rejected by their surroundings. The participant in the present case exhibited the abovementioned traits. Moreover, she was a lonely girl who had lost her friends and confidants.

GAD may seriously interfere with a person's daily life (Wittchen et al., 2002a). With the risk of GAD causing potential torment, people suffering from GAD require treatment. However, some of them cannot attend a long period of treatment sessions. Furthermore, people with low income do not have access to professional help. Therefore, lessening the amount of meeting sessions 
required by mental health professionals is important. Counseling is one of the more affordable methods compared with other psychotherapy techniques (Flanagan \& Flanagan, 2004).

Krumboltz (1965 in Flanagan and Flanagan, 2004) defined counseling as an activity where a counselor assists a client to behave in a certain way to accomplish a solution to problems encountered. Counseling has been used by mental health professionals to help a countless number of people develop effective, satisfying, and productive ways of living (Wampold, Lichenberg, and Waehler, 2002 in Ivey et.al., 2009). In guiding the client, according to Rogers (Austad 2009), the therapist needs to be genuine to express an honest, open, and helpful attitude. Furthermore, the therapist should be an emphatic and sympathetic listener. Those attitudes will create positive unconditional regard for clients. Positive unconditional regard is also known as warmth, acceptance, caring, receiving, or respect (Raskin \& Rogers, 1989 in Austad, 2009). Listening, asking, interpreting, explaining, and giving advice will be done flexibly by the counselor during the counseling concerning the clients' needs. Counseling is appropriately used to diminish the client's worries because the counselor will listen, accept and give positive regard, and understand the client.

Meanwhile, relaxation training benefits clients facing GAD in several ways. Many clients with GAD did not learn how to relax naturally during their development period. Mennin, Heimberg, Turk, and Fresco (2005 in Stevens, 2008) linked GAD symptoms to deficiency in fundamental emotion regulation abilities. Mennin and colleagues showed that heightened emotional intensity, fear of emotional experience, and poor ability in managing negative emotions are related to individuals with GAD (2004 in Stevents, 2008). Maladaptive coping strategies, such as unproductive worry, come from individuals who attempt to control physiological arousal and other aspects of emotional experience. From this perspective, relaxation exercises teach clients new and adaptive ways to manage or prevent excessive physiological arousal and emotional reactivity (Stevens, 2008). Jacobson (1934,1938, 1960 in Stevens, 2008) proposed that anxious individuals might benefit from learning to relax and elongate their muscles. If such individuals learned to create an opposing physiology to their typical muscle tension physiology, perhaps psychological states of anxiety would be alleviated as follow-up. This progressive relaxation can be continued by the clients at home.

Poor ability to manage negative emotion is one of the characteristics of GAD, and people who suffer from GAD need a medium to release their negative emotions. One example is by writing on a journal as a means of recording and sharing what we feel and think to sieve and remove our negative thoughts. Writing is one of the ways that can help acknowledge people and release bad emotions. A diary is a personal journal that is used to record our thoughts and feelings or events that happen each day (Cambridge Dictionary).This study illustrates a specific case and depicts how counseling, progressive relaxation, and writing a journal are effective in reducing GAD symptoms. 


\section{Methods}

\section{Participant}

The participant in this study was recruited randomly from the student counseling center of Universitas Indonesia. Once a student applies in this center, the administrator will request them to write down his/her complaints. From these complaints, we chose one client who described characteristics similar to GAD. After the participant was selected, we conducted an initial interview to gather more information about the symptoms and determine that the complaints from the participant met the criteria for GAD. To gather information, the author used an unstructured interview during the initial interview, studied the client's journal, and determined whether the client fit the criteria on DSM-IV-TR. Many clinicians consider the unstructured approach to be more valid than structured diagnostic interviews containing contrived interview questions (Stevents, 2008). Psychometric tests, namely, DAP, BAUM, HTP, Wartegg, SSCT, and hand test, were also conducted to strengthen the assumptions of diagnosis. These psychological examinations were made to strengthen the allegations in establishing the diagnosis. The participant did not complain about self-harm, suicidal attempts, drug or alcohol abuse, and did not have depression (BDI scores less than 6).

The participant agreed to participate in four sessions of this study (including assessment for baseline) and one follow-up session. The participant was a 21-year-old female named FAF. She was an undergraduate student of Universitas Indonesia and on her sixth semester. She was concerned about her anxiety in several areas in her life since she entered her first semester, and her anxiety had worsened in the sixth semester. She often suffered from chest pain and confusion. During this semester, FAF's friends were out of reach due to their internship, so she had nobody to confide in.

FAF reported that she started worrying about many things and her problems started when she became a college student in Universitas Indonesia. She also claimed to encounter some new cases that she had never experienced before. She became easily upset over the smallest things, such as being jealous over a good-looking girl, feeling disturbed when reading posts on Line or Instagram about feminism and LGBT, and losing her temper at her housekeeper. Her condition apparently did not lead to any avoidance, but she claimed to have chest pain and she started crying every time she would have worrisome thoughts.

FAF provided informed consent as a client on Balai Kesehatan Mahasiswa Klinik Makara Universitas Indonesia. The authors also asked her permission to publish her data in a journal. FAF gave her personal journal to the authors. She wrote the journal with the intention that it would be read by the authors. She addressed her letter to the authors. 


\section{Procedure}

This study used a single case with a multiple baseline design (A-B design). The participant was assigned two sessions weekly at baseline prior to the start of treatment. Each session lasted around 1-2 h. After completing a diagnostic evaluation with an independent evaluator and the participant stating she was eligible, the participant was scheduled for an informed consent meeting with a therapist.

In the last hour of the second week of baseline sessions, the therapist continued with the first session of treatment. Treatment continued in sessions 3 and 4 for approximately $2 \mathrm{~h}$ each session. Treatment strategies aimed to reduce negative automatic thoughts via counseling, hone skills to prevent physical complaint via progressive relaxation, and encourage the participant to express her feelings via a journal used as homework in sessions 2 and 3. At the first session (second meeting) of treatment, the participant was asked to carry out assignments to collect information and know herself better via an $\mathrm{ABC}$ form (find out antecedent, behavior, and consequences in each event) that was discussed in session 3 with the therapist. The participant also wrote a diary for 5 days before the third meeting. At the end of the third session, the participant was asked to continue writing her diary, but she reported not having sufficient time to do so and could only write for 2 days. During the last session, the participant met with the therapist for a final $2 \mathrm{~h}$ treatment/termination session. Following treatment termination, the participant and therapist made an appointment by phone after 2.5 months to complete follow-up assessments consisting of self-report measures.

\section{Case History}

FAF is the eldest child of two siblings. Her parents pampered her wishes, but they would get angry once she was at fault. She had been bullied by her schoolmates since she was in kindergarten, and she did not have any friends in elementary school. Her peers called her names and took her belongings such as stationery and money. She was once asked to write a bad letter for her friends, which only worsened the bullying. She talked to her parents about this situation, but they only suggested that she be brave and refuse when her friends asked for money. Unfortunately, this advice did not work and it made her feel weaker.

In her adolescence, she reported to have bad memories with her parents because of her poor behavior. On one occasion, she asked her mother for help but her mom refused, which made her cry and lose her appetite. Her father called her a spoiled child. She was sad and irritated with their attitude toward her. However, she had great memories at school by having many friends and actively joining extracurricular programs. Even though she had difficulty accepting her parents' attitude, she was happy that she could make her parents proud of her with her acceptance into Universitas Indonesia. 
Her problem with anxiety began when she entered the university. She had an encounter with a previous bully from elementary school, and she was still frightened. She also took her study in the same faculty. In her class, she met and became close friends with two individuals (C and D), who declared that they were attracted to different genders but were still religious. FAF began to be more familiar with information about LGBT either from her friends or social media. One of her friends was attracted to people of the same sex, whereas the other was attracted to both sexes. Between $\mathrm{C}$ and D, FAF preferred to share her story with $\mathrm{C}$ because of their similarities in gender. She described herself as being very selective in choosing friends to share her private stories with because she discovered that her college friends could not be trusted. One day, she told her story to a friend but that story suddenly spread to the entire class. FAF's attitude was influenced by C's preferences, which led her to have interpersonal relationship problems, especially with her mother.

For FAF, the world was not as peaceful as before and she felt that she was in the wrong environment. Nevertheless, she felt comfortable being around them because they were good friends who could accept and understand her. She started to become worried and confused about her friendship, which was comforting, but they did not share the same beliefs. She also believed that God fulfills wishes, such as her wish to have a partner who loves her, regardless of religion and attitude. In her case, God did not grant some of her wishes even if she was religious and did not do bad things. Sometimes, she felt herself become angry with God and thought about no longer praying, but she also did not want to be a sinful person. She started worrying about her future and jealous of other women out of fear that no man would ever love her. She found herself entertaining negative thoughts whenever she logged into her social media accounts on her mobile phone. Unfortunately, she was using her mobile phone as a medium to run away when her mood was becoming bad. Information about LGBT, religious issues, or sexy girls always appeared on her Line and Instagram wall. Furthermore, she claimed to suffer from chest pain and would cry every time her worries crossed her mind.

Admittedly, her situation worsened at the beginning of the sixth semester when her friends, especially $\mathrm{C}$, started focusing on a college project, leaving her feeling secluded. FAF was willing to spend some of her allowance to call $\mathrm{C}$, but the cellular signal in her house was very poor. Consequently, she became easily upset over the littlest things. Her habit of scrolling Line or Instagram increased in frequency, and her topics of interest broadened. Her crying bouts and chest pain complaints also rose.

At home, she felt that no one in her family understood her feelings. Her mother always spoke harsh words to her while her father sometimes spoke in a high intonation like an angry person. Her parents also labeled her as "autistic" because of her preference to keep to herself instead of joining the public. By contrast, her parents and her sister could easily make friends. Her younger sister was always jealous of her, and FAF became very sensitive to her parents' words. She 
started to become worried and confused about her friendship, which was comforting but confusing because she did not agree with their preferences. She would often ask herself why her father talked to her like that, and other negative thoughts also came automatically. FAF's father wished that she would finish her studies soon. She was worried of being unable to accomplish her father's hope, but she wanted to make him proud. FAF was becoming exhausted with her condition and hoped her life would improve with no more worries.

\section{Treatment procedure}

Treatment consisted of three counseling sessions, followed by progressive relaxation at the end of each session. Journal writing was the home assignment at the end of the second and third sessions. FAF was given counseling because she could freely share her emotions, which were usually shared with her friends. The counselor also helped provide insight through summaries, encouragement, and paraphrases. Progressive relaxation was chosen because FAF complained of physical symptoms, so this activity was suggested to help her become more relaxed. Writing a daily journal was chosen by FAF as an alternate source to share her stories and emotions.

\section{Session 1:}

In the first session, the counselor asked FAF to discuss her problem that made her come to the session. FAF immediately shared the problems she had encountered, and she kept changing topics during her story. For example, she would discuss LGBT and then move to another topic, such as her problem with her coach. She spent 30 min enumerating all of her worries. She cried and tore the tissue in her hands when she revealed her problems. When she felt relaxed, the counselor started the question and answer session to understand the root of her problems and listened emphatically to FAF's problems. In the last session, the counselor reflected on the meaning of her problems.

\section{Session 2:}

The second session was used to listen to FAF's complaint and counsel her about the problems raised. FAF was passionate when she spoke; this attitude was evident from her voice tone, clenched fists, and when she hit the table. She sometimes looked as if she was on the brink of crying when she was sharing her problems. In this term, the counselor made FAF realize that she was overanalyzing certain events, which made her feel anxious about the future. FAF's past was also questioned by the counselor to comprehend her behavioral patterns clearly. Thus, the anxiety was shaped, and psychodiagnostic tests (i.e., SSCT, DAP, BAUM, and HTP) were conducted to strengthen the diagnosis. At the end of the session, the counselor advised her to spend time on something she was keen on doing alone (e.g., drawing), reduce social media use, which only worsened her condition, and practice progressive relaxation. FAF was also given journal writing homework. 
Session 3:

This meeting was a continuation of the previous sharing session, followed by a discussion. The results indicate that many alterations were observed in FAF's personality; for example, she was laughing and smiling during the session. She also showed her journal to the counselor, who hoped to be given an opportunity to read it. FAF stated that she was feeling better after writing and having counseling sessions. She also deactivated one of her social media accounts to decrease the intensity of scrolling on social media. The counselor depicted how anxiety formed on FAF, and one reason was her desire for parental attention. She said she lacked attention from her parents, but she was afraid to mention this. She assented to the summary given. As usual, before going home, she was given progressive relaxation, asked to continue writing on her journal, and advised to write a letter to her parents about her concern and wish from them. FAF was pleased because she thought that the relaxation activity was pampering herself due to the relaxed output she received. She was also informed that the next meeting would be the final session due to the improvement made.

\section{Session 4:}

In this session, FAF did not do her homework. She realized her emotions became unstable when she did not write. Writing on her journal was an alternate means for her to express herself given that she had no one to confide in. The counselor continued to listen to her story and discussed some things that could be done to prevent a recurrence. In this meeting, FAF's story contained negative matter regarding her annoyance toward her mother's attitude, but she could restrain her emotion. FAF mentioned that she was not encouraged to write to her parents, and she was also busy with her internship so she could not write on her journal. During the break between the third and fourth sessions, FAF wrote on her journal twice. FAF agreed with the counselor's conclusion about the benefit of writing a journal on her emotions, which influenced her minds and feelings. FAF realized that she needed a medium to share her stories, and she admitted that her journal was an effective means because she was able to explain all of her feelings without being afraid that her secrets would be exposed.

\section{Follow-up}

Follow-up treatment was made by a phone call 2.5 months after the completion of therapy. It consisted of a progress review and a discussion of how relapse could be avoided. FAF reported that her condition was going well, and she could control her thoughts that made her feel anxious. Her worries persisted but only for a few times. She reported that she continued writing on her journal, but only two times since the last session because she had no time. Her habit to see information that triggered her bad mood had decreased, and she claimed that such actions helped her feel much better. 


\section{Analysis}

To gather quantitative information related to reducing GAD symptoms, we used and analyzed the content from FAF's diary. She expressed many kinds of emotions. In this study, we chose to summarize the total number of times the sad and happiness emoticons were used.

\section{Results}

\begin{tabular}{|c|c|c|}
\hline Dates & Sad emoticon & Happiness emoticon \\
\hline June 14, 2017 & 7 & 0 \\
\hline June 15, 2017 & 7 & 0 \\
\hline June 16, 2017 & 6 & 0 \\
\hline June 17, 2017 & 5 & 0 \\
\hline June 18, 2017 & 10 & 0 \\
\hline June 19, 2017 & 2 & 6 \\
\hline
\end{tabular}

Our data showed fluctuating scores; we knew that the level of the sad emoticon use would decline gradually and that of the happiness emoticon would increase. FAF could share her negative feelings in a better manner and in an expressive way via writing on her diary.

Treatment was evaluated through FAF's self-report both in interviews and her journal in the beginning of the session and in the end of the meeting. We analyzed data from FAF's journal, assessment, and observation on her last attendance during the session. At her first day of writing the journal, she mentioned her annoyance over her tendency to overthink many things. This habit did not permit her to live peacefully. At the end of the day, before the fourth session, she claimed that writing a journal helped her release her feelings. She also reported that the counseling sessions made her feel much better. In the last session, she declared that her condition was fine and she was ready to terminate the sessions.

This report demonstrates the role of treatment on GAD on an undergraduate student in Universitas Indonesia. FAF's progress is evident based on her verbal reports and observations made during the final session. Positive alteration was also perceived from her written story on her own journal, which was given to the counselor. In the follow-up session that was done 2.5 months after the last session, she claimed to have a decrease in overthinking and anxiety. During that phase, FAF would still write on her journal and practiced progressive relaxation. For instance, FAF reported that she felt more peaceful because her habit to see unfavorable information had diminished. Furthermore, some of her symptoms had improved. She could easily concentrate, no longer felt irritable, and did not experience sleep disturbances or disruptions. She was able to control her drive to open Line and Instagram. She became more selective in choosing information to read and preferred to use her time to draw.

\section{Adverse Event}

In the third session, FAF became happy and mentioned reuniting with her close friend. She planned to go to her close friend's house after the session; she had not seen this friend during her 
sixth term in college because her friend was on an internship program. Her claim at feeling better was possibly due to her meeting with a close friend whom she had not met for a long time and may not be solely due to the intervention program.

\section{Discussion}

This case adds to the surprisingly limited literature indicating that counseling, progressive relaxation, and writing a journal are effective ways to reduce GAD symptoms on an undergraduate student of Universitas Indonesia. This finding was similar to the results of a previous study, which stated that counseling has small to medium impact on threating anxiety in youth (Erford et al., 2015). Meanwhile, Pakan (2015) reported that counseling is effective to reduce anxiety in individuals age 18 or above. Counseling assisted the participant by building hope through a therapeutic relationship between the client and therapist (Pakan, 2015). In this study, the participant had a chance to meet with a therapist twice during the baseline phase before the intervention was held to allow for trust building that promotes a therapeutic relationship eventually. Despite a study revealing that reducing physiological complaints over GAD is not a result of progressive relaxation (Conrad \& Roth, 2007), progressive relaxation teaches clients new and adaptive ways to manage, or even prevent, excessive physiological arousal and emotional reactivity (Stevens, 2008). Progressive relaxation is a valid treatment to reduce anxiety (Ranjita \& Sarada, 2014). In this case, the client reported physiological complaints and felt more relaxed after the training session. Anxious individuals might benefit from learning to relax and elongate their muscles (Jacobson, 1934,1938, 1960 in Stevens, 2008; Li et al., 2015). Furthermore, writing a journal helps students reduce their stress and anxiety (Murnahan, 2010) by releasing their negative emotions (Kerstner et al., 2015). He found that those who worked on paper-based diaries stay younger than those who worked on any other form of journaling. Through journaling, people could express their feelings in their own way.

Notably, therapy gains were achieved solely through the program. These findings may help clients with limited resources because they can write a journal and practice progressive relaxation by themselves at home so that they only need to meet professionals as few times as possible. Nevertheless, in the follow-up session, the client reported that she still continued writing a journal in two occasions, so that the claim that the length of intervention was only held three times was not in line with the termination of the program as complete.

This study had several limitations. First, the authors did not use diagnostic screening tools to measure the level of anxiety at baseline and during intervention. Second, the follow-up session was too short, so we cannot say that the intervention was absolutely effective. Third, writing is a skill, and writing a journal is not suitable for clients who are illiterate. Fourth, we cannot generalize the result because the sample number was limited. Fifth, this finding may only suit a typical client with no access to share her feelings because of the criteria of the sample. Sixth, we could not control any other situation that would influence the results, such as meeting with her close friend in the third session. 


\section{References}

American Psychiatric Association. (2000). Diagnostic and statistical manual of mental disorders (4th ed., textrev.). Washington, DC: Author.

Austad, Carol.S. 2009. Counseling and psychotherapy today: theory, practice, and research. New York: McGraw-Hill International Edition.

Flanagan, John. S., Flanagan, Rita. S. (2004) Counseling and psychotherapy theories in context and practice: skills, strategies, and techniques. New Jersey: John Wiley \& Sons, Inc.

Hall, C.S., Lindsey, G., \& Campbell, J.B. (1998). Theories of personality (4 ${ }^{\text {th }}$ Ediiton). New York: John Willey \& Sons, Inc.

Ivey, Allen.E., Andrea, Muchael.D., Ivery, Mary.B.,Morgan, Lynn.S. (2009). Theories of counseling and psychotherapy sixth edition. USA: Pearson International Edition.

Oxford Dictionary.com

Will, Frank. (2009). Beck's cognitive therapy: The CBT distinctive features series. New York: Routledge

Stevens, Holly.H. (2008). Psychological approaches to generalized anxiety disorder. USA: Springer Science + Business Media, LLC

Wittchen, H.U., 2002a. Generalized anxiety disorder: prevalence burden, and cost to society. Depress. Anxiety 16, 162-171

Erford, B., Kress, V., Giguere, M., Cieri, D., and Erford, B. (2015) Meta-analysis: Counseling Outcomes for Youth with Anxiety Disorders. Journal of Mental Health Counseling: January 2015, Vol. 37, No. 1, pp. 63-94

Pakan, Jessica A., "Counseling to Reduce Stress and Anxiety: A Mixed Methods Study" (2015). Counselor Education Capstone. 3. http://digitalcommons.brockport.edu/edc_capstone/3

Li, Y., Wang, R., Tang, J., Chen, C., Tan, L., Wu, Z., ... Wang, X. (2015). Progressive Muscle Relaxation Improves Anxiety and Depression of Pulmonary Arterial Hypertension Patients. Evidence-Based Complementary and Alternative Medicine: eCAM, 2015, 792895. http://doi.org/10.1155/2015/792895

Conrad, A. \& Roth, W. T. (2007). Muscle relaxation therapy for anxiety disorders: It works but how?. Journal of Anxiety Disorders 21 (2007) 243-264

Ranjita, L. \& Sarada, N. (2014). Progressive Muscle Relaxation therapy in Anxiety: A Neurophysiological Study. IOSR Journal of Dental and Medical Sciences (IOSR-JDMS) e-ISSN: 2279-0853, p-ISSN: 2279-0861.Volume 13, Issue 2 Ver. I. (Feb. 2014), PP 25-28 www.iosrjournals.org

Murnahan, Briana, "Stress and Anxiety Reduction Due to Writing Diaries, Journals, E-mail, and Weblogs" (2010). Senior Honors Theses. 230. http://commons.emich.edu/honors/230

Kerstner, T., Mier, D., Rist, F., Witthöft, M., Diener, C., Bailer, J. (2015). A Diary-Based Modification of Symptom Attributions in Pathological Health Anxiety: Effects on Symptom Report and Cognitive Biases. Journal of Consulting and Clinical Psychology (C) 2015 American Psychological Association 2015, Vol. 83, No. 3, 578-589 